\title{
Prática e Conteúdo Estratégico em Redes de Empresas: estudo no APL de metais sanitários de Loanda/PR.
}

\author{
Julio Ernesto Colla \\ Sergio Bulgacov ${ }^{2}$
}

\section{Resumo}

O presente artigo busca descrever as principais práticas estratégicas existentes na rede constituída pelas empresas que compõem o Arranjo Produtivo Local (APL) de Metais Sanitários de Loanda, Paraná. O referencial teórico trata da estratégia como prática e conteúdo estratégico em rede de empresas. Foram adotadas duas metodologias independentes e complementares: primeiramente, uma fase exploratória e qualitativa decorrente da estrutura teórica para o delineamento das categorias de análise; em seguida, a pesquisa do tipo levantamento para a aplicação do estudo à população constituída pelas empresas integrantes do Arranjo Produtivo Local. Os procedimentos metodológicos, portanto, foram múltiplos e de natureza descritiva e explicativa. Os principais encontros indicam que os dirigentes das empresas estudadas adotam um processo de estratégia informal e simplificado, havendo grande transferência das práticas estratégicas entre os gestores e com a adoção de três posturas distintas: a) comportamento recatado; b) os que tendem a se reunir com pessoas do ramo; e c) os que conversam com pessoas de fora do ramo de metais sanitários.

Palavras-chave: Prática Estratégica. Conteúdo Estratégico. Redes de Empresas.

\section{Introdução}

A abordagem da estratégia como prática busca compreender melhor o ato de se fazer estratégia, com as interações entre os diferentes atores sociais,

\footnotetext{
${ }^{1}$ Mestre em Administração pelo CEPPAD/UFPR. Professor do Departamento de Administração da UNESPAR/FAFIPA. Endereço: Universidade Federal do Paraná, Setor de Ciências Sociais Aplicadas, Departamento de Administração Geral e Aplicada. Rua Prefeito Lothário Maissner, 632. Jardim Botânico. CEP 80210-170 - Curitiba, PR. E-mail: juliocolla@gmail.com.

${ }^{2}$ Pós-Doutor pela University of Birmingham. Professor Associado dos Cursos de Mestrado, Doutorado e Graduação em Administração da Universidade Federal do Paraná. Endereço: Universidade Federal do Paraná, Setor de Ciências Sociais Aplicadas, Departamento de Administração Geral e Aplicada. Rua Prefeito Lothário Maissner, 632. Jardim Botânico. CEP 80210-170 - Curitiba, PR. E-mail: s.bulgacov@ufpr.br. Artigo recebido em: 25/01/2009. Aceito em: 30/06/2009. Membro do Corpo Editorial Científico responsável pelo processo editorial: Gilberto de Oliveira Moritz.
} 
utilização de ferramentas estratégicas e dos efeitos das ações dos estrategistas e de outros atores responsáveis por fazer a estratégia e os resultados acontecerem. A importância teórica da utilização das perspectivas de análise adotadas neste artigo é a contribuição para o entendimento das práticas estratégicas em um contexto de rede econômica e social.

Desse modo, pressupõe-se que a prática estratégica em rede de empresas pode ser influenciada por diversas características organizacionais, em especial: a associatividade ou não das organizações envolvidas e, em se tratando de rede de empresas produtoras de bens de consumo, se existem posturas estratégicas diferenciadas entre os gestores das empresas com relação ao enquadramento das organizações quanto ao seu conteúdo estratégico, pois o conjunto ambiental no qual uma organização está submetida reflete-se diretamente sobre o ato de fazer a estratégia, possibilitando vasto campo de estudos. Destaca-se que descrições em torno das práticas estratégicas e dos atores envolvidos podem contribuir para a identificação de seus instrumentos, conceitos e perspectivas, bem como das habilidades necessárias para seu exercício.

O presente artigo busca descrever as práticas estratégicas existentes na rede constituída pelas empresas que compõem o APL de Metais Sanitários de Loanda - PR. Para melhor operacionalização, tal objetivo foi especificado em: descrever o APL de Metais Sanitários por meio da condição de associação e do conteúdo estratégico das empresas integrantes; analisar as principais práticas estratégicas; correlacionar as principais práticas adotadas; verificar se existe influência nas práticas estratégicas com a situação de associatividade e de conteúdo estratégico; e, por fim, determinar se existem diferenças na ação estratégica dos empresários de acordo com o agrupamento em que a empresa está inserida.

Para atingir o objetivo proposto, este artigo está estruturado em cinco seções, incluída esta seção inicial. A segunda é representada pelo referencial teórico-empírico, em que são apresentados os conceitos relativos à estratégia como prática e conteúdo estratégico em rede de empresas. Na terceira seção são apresentadas as condutas metodológicas que foram empregadas na pesquisa. A quarta seção, subdividida pelas fases da pesquisa, apresenta os dados e analisa os resultados. Por fim, uma seção em que são apresentadas as conclusões do artigo. Na sequência é apresentado a bibliografia utilizada. 
Prática e Conteúdo Estratégico em Redes de Empresas: estudo no APL de metais sanitários de Loanda/PR.

\section{Referencial Teórico-Empírico}

\subsection{A Estratégia Como Prática}

A concepção de estratégia como prática social é parte de um movimento contemporâneo criado por pesquisadores europeus, em que se procura estudar aspectos que se inserem no interior do trabalho de elaborar estratégias, buscando, basicamente, compreender questões relativas à elaboração, ao trabalho, às habilidades necessárias e sua possível aquisição. Preocupa-se, também, com a criação da estratégia, das técnicas e indagações sobre geração, publicidade e consumo do conhecimento. Menos positivista que a escola americana, tem sua legitimidade na importância das organizações para a sociedade e no quanto a estratégia é importante para elas, pois envolve recursos consideráveis $e$ as consequências de ações equivocadas causam grandes prejuízos sociais.

Em função disso, é preciso determinar quais são os elementos básicos processos, mecanismo e custo - da prática da estratégia (WHITTINGTON, 2003; 2004; CLEGG; CARTER; KOMBERGER, 2004). A estratégia como prática não rompe com os conceitos - conteúdo e processo - estabelecidos no campo, mas os integra, procurando elucidar novas questões. Para tanto, é necessária uma integração científica, não o rompimento com o modernismo, mas o desenvolvimento de um conhecimento da prática social. Portanto, para realizar mudança na área da estratégia, Whittington (2004) acredita que é necessária maior pluralidade de práticas fornecidas pelo "após modernismo" que não é um movimento de ruptura com o modernismo como é/foi o pósmodernismo. O "após modernismo" prega uma formulação mais inclusiva, que incorpora o conhecimento desenvolvido no modernismo em um contexto mais amplo da prática social (WHITTINGTON, 2002; 2004).

Entre os teóricos da estratégia como prática social, há a inquietação em pesquisar a maneira como os estrategistas e seus artefatos atuam mutuamente, ou seja, a perturbação é relacionada à prática de "estrategiar" (strategizing) em um contexto histórico-cultural. Em função disso, há uma preocupação em detalhar as atividades cotidianas nas organizações, que estão relacionadas ao strategizing com o intuito de entender o do and say dos atores quando estão "estrategiando". Nesse sentido, a estratégia é tida como um fluxo de atividades em constante processo de (des)construção, passando o foco a ser 
as micro atividades, sem que, reafirma-se, deixar-se tomar pelo reducionismo (DENIS; LANGLEY; ROULEAU, 2004; WHITTINGTON, 1996; 2003; 2004; JARZABKOWSKI, 2003; 2005).

Surge então uma proposta dupla em que se contemplam os anseios de pesquisadores e práticos em estratégia. A primeira agenda, a da teorização ou sociológica, busca criar uma teoria estratégica baseada nos conhecimentos das teorias sociais, tendo nos acadêmicos seu público e nível de análise, pois considera a estratégia como um amplo campo de atividade social. A segunda agenda, a da ação ou gerencialista, busca refletir melhor o trabalho $e$ as preocupações dos praticantes, tendo como nível de análise os praticantes, ou seja, a performance do estrategista. As duas agendas não são desconexas e distantes, e o diálogo entre elas é a proposta da estratégia como prática que privilegia a análise da performance do estrategista em relação à organizacional (WHITTINGTON, 2004; WILSON; JARZABKOWSKI, 2004).

As agências - iterativa, projetiva e prática-avaliativa - em que os estrategistas podem se engajar, perfazem três dimensões complementares e podem auxiliar na compreensão do processo de se fazer estratégia. A iterativa, próxima à animation do processo de strategizing, lida com a reprodução seletiva dos atores de modelos prévios e tende a reproduzir a prática existente. Na dimensão projetiva, de conotação voluntarista, encaixam-se as projeções imaginativas de futuro, representando a orientation do processo de strategizing. A terceira agência, a prática-avaliativa, representa a maior preocupação da estratégia como prática. Busca a sabedoria da prática e pretende que os atores reflitam sobre suas atuações momentâneas e futuras, inseridas no contexto. Essa dimensão compreende o pensar e o agir estrategicamente (WILSON; JARZABKOWSKI, 2004).

Dentro desse contexto, baseado nas agendas e agências e diante das publicações científicas, expõe-se uma estrutura de temas e áreas para que seja criada uma categoria analítica, exposta a seguir, cuja função, neste trabalho, é oferecer lentes teóricas para a análise. Esse framework, apresentado no quadro abaixo, é composto de Capacidades e Conhecimento, Atores não Humanos, Contexto, Ética, Identidade Profissional, Instituições, Linguagem, Poder, Resultados e Stakeholders (CLEGG;CARTER; KOMBERGER, 2004; WILSON; JARZABKOWSKI, 2004; WHITTINGTON, 2004). 


\begin{tabular}{|c|c|}
\hline Item & Descrição do conceito e necessidade de estudo \\
\hline $\begin{array}{l}\text { Capacidades e } \\
\text { Conhecimento }\end{array}$ & $\begin{array}{l}\text { O conhecimento que o estrategista tem do mercado e da organização influencia a } \\
\text { prática da estratégia? Essa dúvida também auxilia na compreensão da estratégia } \\
\text { como prática. Nesse elemento, também devem ser colocados os questionamentos } \\
\text { em relação à educação formal do estrategista (WILSON; JARZABKOWSKI, 2004). }\end{array}$ \\
\hline $\begin{array}{l}\text { Atores não } \\
\text { Humanos }\end{array}$ & $\begin{array}{l}\text { Tentativa de relacionar os elementos envolvidos na formulação da estratégia, visto } \\
\text { que alguns pontos não são exclusivamente consequência de atos humanos na for- } \\
\text { mulação de estratégias empresariais (CLEGG; CARTER; KOMBERGER, 2004). }\end{array}$ \\
\hline Contexto & $\begin{array}{l}\text { A estratégia como prática é influenciada pelo contexto em que os estrategistas e } \\
\text { organizações se encontram? Apesar de pesquisadores descreverem a importância } \\
\text { do contexto organizacional, houve pouca demonstração de interrelacionamento } \\
\text { entre o contexto e o processo de strategizing (WILSON; JARZABKOWSKI, } 2004 \text {. }\end{array}$ \\
\hline Ética & $\begin{array}{l}\text { Em formulação de estratégia, a ética permanece silenciosa ao longo dos tempos e a } \\
\text { grande dúvida é: em que ética as estratégias devem ser embasadas? Essa dúvida é } \\
\text { pertinente no momento que o ambiente competitivo estimulou ações que fizeram } \\
\text { alguns estrategistas perderem os limites éticos (CLEGG; CARTER; KOMBERGER, } \\
\text { 2004). }\end{array}$ \\
\hline Instituições & $\begin{array}{l}\text { A busca da legitimidade, enunciada pela teoria neo-institucional, explica algumas } \\
\text { ações empresariais, porém existe a possibilidade de haver isomorfismo } \\
\text { organizacional. Diante disso, a estratégia criou determinados ritos, mas correndo o } \\
\text { risco de se tornar desalinhada ao ambiente organizacional (CLEGG; CARTER; } \\
\text { KOMBERGER, 2004). }\end{array}$ \\
\hline Poder & $\begin{array}{l}\text { É necessário, para que se entendam as decisões tomadas e seu porquê, bem como } \\
\text { a forma como as elites dominantes exercem pressão e controle no processo estraté- } \\
\text { gico (CLEGG; CARTER; KOMBERGER, 2004). }\end{array}$ \\
\hline $\begin{array}{l}\text { Resultados } \\
\text { da Estratégia }\end{array}$ & $\begin{array}{l}\text { As questões relativas aos resultados das estratégias devem ser atribuídas aos estra- } \\
\text { tegistas ou às organizações? A quem os resultados interessam: aos estrategistas ou } \\
\text { às organizações (WHITTINGTON, 2004)? }\end{array}$ \\
\hline Stakeholders & $\begin{array}{l}\text { Há o mesmo processo de strategizing diante de stakeholders diferentes (WILSON; } \\
\text { JARZABKOWSKI, 2004) ou os estrategistas são influenciados por eles? }\end{array}$ \\
\hline Linguagem & $\begin{array}{l}\text { É interessante conhecer a linguagem da estratégia e a maneira como o estrategista } \\
\text { entende a realidade; compreender como a linguagem interfere no processo de criação } \\
\text { de estratégia, bem como porque essa linguagem oferece um mapa para o futuro e a } \\
\text { habilidade de se formular problemas que ela própria possa solucionar. A linguagem da } \\
\text { estratégia representa também os microfenômenos relacionados ao discurso e a gestos } \\
\text { (CLEGG; CARTER; KOMBERGER, 2004; WILSON; JARZABKOWSKI, 2004). }\end{array}$ \\
\hline $\begin{array}{l}\text { Identidade } \\
\text { Profissional }\end{array}$ & $\begin{array}{l}\text { A falta de conhecimento de quem são os estrategistas acumula um ônus sobre a estra- } \\
\text { tégia como prática, porque existe a grande dúvida do que os estrategistas realmente } \\
\text { fazem quando formulam a estratégia (CLEGG; CARTER; KOMBERGER, 2004). }\end{array}$ \\
\hline
\end{tabular}

Quadro 1: Conceitos e necessidades de estudos em estratégia como prática. Fonte: Clegg, Carter e Komberger (2004) e Wilson e Jarzabkowski (2004). 
Os trabalhos de estratégia como prática não devem ficar restritos à análise micro, pois teriam seu valor reduzido. É preciso, pois, lidar com elementos de níveis micro e macro. As relações ou as influências que as práticas no nível de análise micro exercem sobre o outro nível, e vice-versa, revelam o que se qualifica como as ciladas para o campo. Nesse caso, existe ainda a possibilidade da análise ficar em nível inferior e condenar a corrente europeia ao isolamento. Portanto, é necessário o relacionamento do nível micro - atividades práticas - com o nível macro - resultados das organizações sociais, políticas e econômicas. (WHITTINGTON; JOHNSON; MELIN, 2004; WHITTINGTON, 2004; WILSON; JARZABKOWSKI, 2004).

Portanto, a estratégia como prática busca a compreensão do dia a dia da formulação da estratégia, sendo necessária uma verificação extensa do que venham a ser a comunicação, as reuniões, os gestos, os discursos e os escritos para essa formulação, integrando os níveis micro e macro de análise (WHITTINGTON, 2003; 2004).

\subsection{Conteúdo Estratégico em Redes de Empresas}

O conteúdo estratégico, sob a perspectiva das atividades empresariais, está relacionado a "o que" e "para quem" determinadas ações são efetuadas, ou seja, o posicionamento da empresa em termos de produtos e mercados, sem deixar de se preocupar com seu desempenho (BULGACOV, 1997; BULGACOV et al., 2007), e a questão central de pesquisas relacionadas a conteúdo estratégico diz respeito à relação entre condições ambientais, estratégicas corporativas ou de unidades de negócio e desempenho econômico (GIMENEZ, 2000). O conteúdo estratégico trata das ideias, intenções, proposições e sua lógica interna, suas mútuas influências, articulações, e eventuais discrepâncias ou incongruências, pois a perda da noção do escopo principal e os erros na oferta de produtos e serviços aos mercados são claramente erros do conteúdo estratégico, já que esses equívocos mercadológicos dãose nos elementos mercado, produtos, foco e resultados estratégicos (BULGACOV et al., 2007; MEIRELLES; GONÇALVES, 2000; CHAKRAVARTHY; DOZ, 1992). Esses erros podem ser atribuídos à insuficiente capacidade de interpretação das variáveis envolvidas (FIGUEIREDO; ZAMBOM, 2005).

Os estudos acerca de conteúdo estratégico que consideram os produtos, os mercados e os resultados de sua interação (CHAKRAVARTHY; DOZ, 
1992 ) estão constantemente sujeitos a novos desafios. Se, por um lado, as estratégias que levam à diversificação dos produtos e ampliação dos mercados mostram-se atrativas para os dirigentes, ao mesmo tempo elevam os riscos de desapontamento face às inúmeras dificuldades encontradas durante processos de mudança.

Outra vertente de estudos sobre conteúdo estratégico procura ir além da relação entre a estratégia e seus resultados. Busca-se, cada vez mais, verificar a complexa relação entre o foco, os resultados e o amplo conjunto de variáveis ambientais externas e internas da organização (GRANT, 2002). Nesse caso, uma das abordagens mais promissoras procura identificar relações entre recursos, capacidades, estruturas e implementação de estratégias, levantando novamente a questão da importância do alinhamento estratégia e resultados coletivos.

É válido ressaltar que o pensamento atual acerca de pesquisas sobre conteúdo estratégico decorre do trabalho de Ansoff (1957), em que o autor propõe a matriz produto-mercado, ainda muito utilizada nessas pesquisas. Após o trabalho de Ansoff (1957), outros estudos apresentam-se importantes, como os trabalhos de Chakravarthy e Doz (1992), os quais inserem a ideia de resultados; Porter (2004) destaca o posicionamento dentro dos elementos acima citados; e, recentemente, Bulgacov et al. (2007) colocam o foco estratégico influenciando os outros elementos componentes do conteúdo estratégico. Dessa forma os elementos constituintes do conteúdo estratégico são: produto, mercado, resultado e foco (BULGACOV et al., 2007).

Nesse sentido, um dos principais desafios enfrentados pelas empresas hoje se encontra na ampliação do foco por meio de parcerias, alianças estratégicas e redes. Novas conceituações em termos de foco, mercado, produto e resultado funcionam cada vez mais para um conjunto de organizações interdependentes e não apenas para cada organização de forma independente.

Dessa forma, em redes de empresas as organizações possuem posturas diferentes em relação ao conteúdo estratégico, o que é representado graficamente pela Figura 1 na página seguinte.

Diante disso e considerando a abordagem de redes de empresas, as organizações apresentam as seguintes características: empresas ativas quanto ao conteúdo estratégico, caracterizadas por organizações que, em redes, possuem a capacidade de agir e modificar os elementos constituintes do conteúdo estratégico, ou seja, exercem liderança nos elementos produtivos e são 


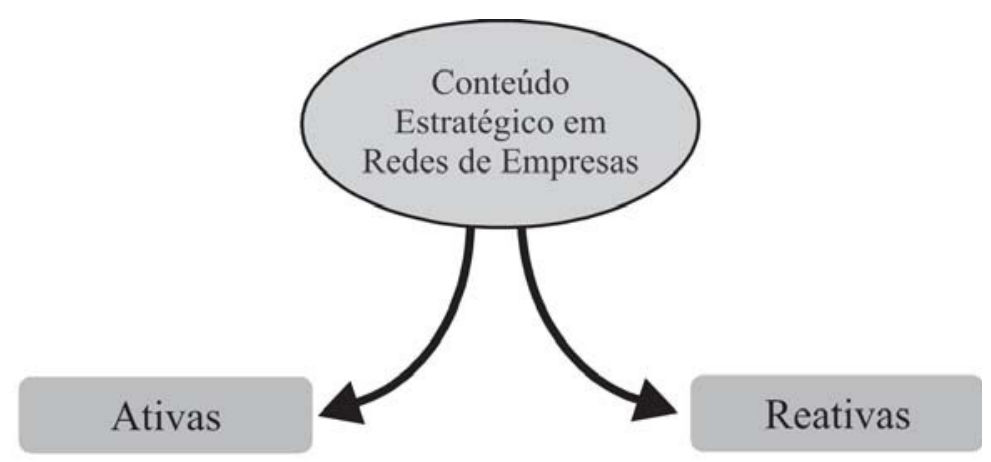

Figura 1: Conteúdo Estratégico em Redes de Empresas.

Fonte: Dados primários.

constituídas com a finalidade de produção de bens de consumo; e empresas reativas quanto ao conteúdo estratégico, caracterizadas por organizações que, em redes, apenas refletem em suas operações desejos de outras organizações, ou seja, possuem uma espécie de passividade estratégica e operacional em relação às ativas. São caracterizadas como prestadoras de serviços para as empresas ativas, apesar de exercerem função importante na rede.

\section{Metodologia}

Com a intenção de apresentar a sistematização do caminho percorrido, assegurar a validação e confiabilidade do estudo, bem como dar apoio à réplica, essa seção apresenta a metodologia para a solução do problema de pesquisa, pois as pesquisas sobre estratégia, assim como pesquisa em estratégias como prática, geralmente são orientadas por questões de difícil investigação empírica, principalmente no que diz respeito à sua formação, implemento e gerenciamento ao longo do tempo (PETTIGREW, 1992; MINTZBERG, 1988).

O trabalho utilizou duas abordagens independentes e complementares: primeiramente, uma fase exploratória, predominantemente qualitativa, para o delineamento das categorias de análise; em seguida, a pesquisa do tipo levantamento, para a aplicação do estudo à população constituída pelas empresas integrantes do Arranjo Produtivo Local de Metais Sanitários de Loanda - PR. Os procedimentos metodológicos, portanto, foram múltiplos e de natureza descritiva e explicativa. O método combinado permite melhor 
compreensão a respeito das categorias de análise propostas, em especial em estudos em estratégia (CRESWELL, 2007; FLICK, 2004; RICHARDSON, 1999; MAY, 2004). Portanto, a perspectiva temporal da pesquisa pode ser caracterizada como do tipo transversal, com aproximação longitudinal (RICHARDSON, 1999), em função de questionamentos sobre os processos estratégicos.

O APL estudado é formado por 36 empresas. Para fins deste trabalho foram pesquisadas 34, visto que duas são formações empresariais decorrentes dessas 36, com gestão compartilhada, sendo 13 associadas à Associação das Indústrias de Metais Sanitários de Loanda e Região (AIMES) e 21 nãoassociadas. Sob a perspectiva do conteúdo estratégico, 25 são consideradas ativas e nove reativas. Na primeira fase da pesquisa foram realizadas entrevistas com seis dirigentes de empresas associadas e cinco entrevistas com dirigentes de empresas não-associadas, além de uma entrevista em três etapas com o secretário geral da associação. Na segunda fase foram aplicados questionários aos 34 dirigentes das empresas que compõem o APL de Metais Sanitários. Dessa forma, o nível de análise foi constituído pelas empresas envolvidas e, consequentemente, pela rede organizacional. A unidade de análise foi cada um dos dirigentes das empresas.

$\mathrm{Na}$ primeira fase foram aplicadas entrevistas com uso de roteiro semiestruturado, observação não participante e análise documental. Para essa etapa utilizou-se o critério de tempo e existência e acessibilidade para a amostragem não-probabilística intencional. Essa fase de coleta foi esgotada pelo critério da exaustão dos dados coletados. Para o tratamento dos dados qualitativos foi utilizada a análise de conteúdo, e para a análise dos dados qualitativos sua tabulação em categorias (FLICK, 2004; CRESWELL, 2007). Para análise dos documentos coletados foi utilizada a técnica de análise documental (MAY, 2004). A triangulação dos dados obtidos nas entrevistas, nos documentos das empresas, nas observações e nos questionários auxiliou na compreensão das categorias pesquisadas. Na segunda fase, quantitativa, aplicou-se questionários estruturados para a totalidade da população pesquisada.

O tratamento dos dados foi efetuado de acordo com as fases da coleta dos dados. Na fase 1 - qualitativa - as entrevistas semi-estruturadas foram transcritas e expostas à análise de conteúdo (BARDIN, 1977; FLICK, 2004; RICHARDSON, 1999) por meio da proximidade de conteúdo e extração de grupos de ações que refletiam a lógica das atividades. Nessa fase, foram incluídos no mesmo formato de análise os dados secundários da pesquisa. A 
fase 2 - quantitativa - contou com o auxílio do pacote estatístico SPSS ${ }^{\circledR}$ for Windows ${ }^{\circledR}$. Os testes de estatística descritiva utilizados foram os relativos à frequência, descrição da amostra e cruzamento dos dados; e os de estatística não-paramétrica foram o teste de correlação de Spearman, o teste U, para verificação de diferenças entre pequenos grupos, e o teste de Kruskal Wallis, para mensuração de diferenças entre os clusters do agrupamento base da pesquisa.

Sob a perspectiva do teste de aglomeração, optou-se por quatro agrupamentos em função dos percentuais mais equilibrados entre cada um dos grupos componentes. A composição dos quatro clusters utilizados por este trabalho é representada pela Tabela 1, a seguir, e informa a concentração das empresas estudadas. As empresas associadas estão concentradas nos clusters 2 e 3, ao passo que a maior concentração das empresas não-associadas está nos clusters 1 e 4 . Sob a ótica das empresas ativas e reativas ao conteúdo estratégico, a composição dos clusters informa a concentração das empresas ativas em ordem de ocorrências nos clusters 4, 3, 2 e 1. As empresas reativas concentram-se totalmente no 1.

As empresas com as menores médias de faturamento encontram-se no cluster 1 , seguidas das que compõem o cluster 4 , cluster 3 e cluster 2 . É válido salientar a agudez quanto ao faturamento dos clusters 2 e 3 . A apresentação da amostra estudada, caracterizada nesta seção, tem como objetivo servir de base para as análises dos objetivos do presente trabalho.

\section{Elementos de Análise}

\subsection{Análise Qualitativa}

Os empresários associados, de maneira geral, iniciaram suas atividades por meio de algum tipo de relacionamento com o empresário pioneiro. A influência é demonstrada nas entrevistas quando questionados sobre os motivos que levaram os entrevistados a empreender no ramo de metais sanitários. Os dados da pesquisa apresentam, nas empresas associadas, grande influência tanto gerencial quanto pessoal da empresa pioneira, refletindo nas práticas individuais, caracterizada pela simplicidade e informalidade, fato que já havia sido constatado pelo Instituto Paranaense de Desenvolvimento Eco- 
Prática e Conteúdo Estratégico em Redes de Empresas: estudo no APL de metais sanitários de Loanda/PR.

Tabela 1: Distribuição das empresas associadas, não-associadas, ativas e reativas por cluster.

\begin{tabular}{|c|c|c|c|c|c|c|c|}
\hline & & & \multicolumn{4}{|c|}{ Cluster Base } & \multirow{2}{*}{$\begin{array}{l}\text { Total } \\
13\end{array}$} \\
\hline & & & 1 & 2 & 3 & 4 & \\
\hline \multirow{4}{*}{$\begin{array}{l}\text { Quanto à } \\
\text { associatividade }\end{array}$} & \multirow[t]{2}{*}{ Sim } & Quantidade & 2 & 5 & 4 & 2 & $38,2 \%$ \\
\hline & & \% do Cluster & $18,2 \%$ & $83,3 \%$ & $57,1 \%$ & $20,0 \%$ & 21 \\
\hline & \multirow[t]{2}{*}{ Não } & Quantidade & 9 & 1 & 3 & 8 & $61,8 \%$ \\
\hline & & $\%$ do Cluster & $81,8 \%$ & $16,7 \%$ & $42,9 \%$ & $80,0 \%$ & 34 \\
\hline \multicolumn{2}{|l|}{ Total } & Quantidade & 11 & 6 & 7 & 10 & $100 \%$ \\
\hline \multicolumn{3}{|c|}{ Percentual Total } & $100 \%$ & $100 \%$ & $100 \%$ & $100 \%$ & 25 \\
\hline \multirow{4}{*}{$\begin{array}{l}\text { Quanto ao } \\
\text { Conteúdo } \\
\text { Estratégico }\end{array}$} & \multirow[t]{2}{*}{ Ativa } & Quantidade & 2 & 6 & 7 & 10 & $73,5 \%$ \\
\hline & & $\%$ do Cluster & $18,2 \%$ & $100,0 \%$ & $100,0 \%$ & $100,0 \%$ & 9 \\
\hline & \multirow[t]{2}{*}{ Reativa } & Quantidade & 9 & 0 & 0 & 0 & $26,5 \%$ \\
\hline & & $\%$ do Cluster & $81,8 \%$ & $0 \%$ & $0 \%$ & $0 \%$ & 34 \\
\hline \multicolumn{2}{|l|}{ Total } & Quantidade & 11 & 6 & 7 & 10 & $100 \%$ \\
\hline \multicolumn{2}{|l|}{ Percentual Total } & & $100 \%$ & $100 \%$ & $100 \%$ & $100 \%$ & \\
\hline
\end{tabular}

Fonte: Dados primários.

nômico e Social (IPARDES) no estudo sobre o APL de Metais Sanitários de Loanda (IPARDES, 2006).

As empresas não-associadas são mais jovens que as associadas; originaram seus empreendimentos em função do sucesso dos outros empresários, e não em função de contato com o empresário pioneiro. Vale destacar a existência de um empresário não-associado que trabalhou nas operações da empresa pioneira quando era garoto, com 11 anos de idade, fazendo faxina, para, posteriormente, passar por outros setores operacionais da empresa. Porém, esse hoje empresário não entrou no ramo em função de incentivo do empresário pioneiro, mas pelo fato de ter encontrado um sócio, há três anos, recém chegado do Japão com capital para iniciar uma empresa e buscava um empreendimento para investir.

O exposto acima auxilia na compreensão do fenômeno estudado, ou seja, a busca do entendimento das práticas estratégicas dos empresários do APL de Metais Sanitários.

Capacidades e Conhecimento: em relação às capacidades e conhecimentos dos gestores das empresas associadas, encontrou-se uma diversidade de formações que pode auxiliar na compreensão das simplificadas técni- 
cas gerenciais utilizadas pelos empresários, que têm origem em diversas atividades comerciais: um era caminhoneiro (entrevistado 1), outro era pasteleiro (entrevistado 2), outro, ainda, era proprietário de casa de boliche (entrevistado 4), antes de entrarem no ramo atual. Ainda foi encontrada uma fonoaudióloga (entrevistado 5) que entrou no ramo dos metais sanitários em função de que o negócio da família estava em crescimento. Apenas um entrevistado tinha breve experiência trabalhando na empresa pioneira, porém, não trabalhava em cargos gerenciais. Não há formação específica em negócios entre os gestores em nenhuma das classificações utilizadas por este trabalho.

Atores não Humanos: no presente estudo, a contribuição de elementos alheios a atos humanos é encontrada em uma missão internacional à Itália, que perdurou por 15 dias e teve a participação de doze empresários, com o objetivo de criar uma joint-venture com empresas italianas, fato que não foi concretizado. Nessa visita, os empresários observaram diversas práticas gerenciais não constantes no seu dia a dia, conforme revelam os relatos a seguir:

[...] a viagem para a Itália deu um salto na compreensão de que sozinhos eles não iam progredir em relação ao mercado [...] e lá eles viram mais coisa ainda, começaram a ver terceirizadas, hoje as empresas já estão com a mentalidade... os empresários já estão com a mentalidade que eles não precisam fazer o processo inteiro, [...] eles pode... criar braços pra estar fazendo serviços [...] (Entrevistado 10).

Quando eu voltei de lá, porque lá eu vi que se terceiriza muita coisa [...] aí o que eu fiz? Eu vim de lá com essa ideia: eu vou chegar no Brasil e vou terceirizar, e, realmente terceirizei bastante coisa [...] (Entrevistado 01).

A existência da missão à Itália pode ser considerada um elemento bastante presente na formulação da estratégia nas organizações associadas e ativas quanto ao conteúdo estratégico. A missão empresarial à Itália também serve como evidência para o conceito utilizado neste trabalho de que, em rede de organizações produtoras de bens de consumo, existem empresas reativas ao conteúdo estratégico. 
Nas organizações não-associadas e reativas ao conteúdo estratégico não foram encontrados indícios da presença de atores não humanos como auxiliar na formulação da estratégia.

É válido lembrar que todas as atividades são, em última análise, decorrentes de atos humanos, porém, a diferença, tal como exemplificada por Clegg, Carter e Komberger (2004, p. 28), está em não "desprezar algo do qual não se podem tirar lições ou que deva ser ignorado", como as falhas mecânicas que derrubaram o avião que levava o ator cujo conselho teria feito a diferença; os vírus que apagou as estratégias do computador do estrategista ou os colapsos dos mercados que "levaram tudo pelos ares".

Contexto: dentre os elementos apresentados na base teórica, o contexto é o que se mostra mais presente no strategizing dos empresários do APL de Metais Sanitários, pois os negócios dos associados foram iniciados em circunstâncias semelhantes. As empresas surgiram em torno da empresa pioneira que, atualmente, não é mais gerenciada pelo fundador. Novas empresas surgiram porque a empresa pioneira necessitava aumentar a produção e não tinha capacidade financeira e gerencial para essa expansão, fato que deu origem ao que hoje é chamado pelos empresários de terceirizadas, às quais este trabalho denomina de empresas reativas ao conteúdo estratégico. Os entrevistados 1, 2 e 3 possuem passagens semelhantes em relação às condições iniciais que cercavam seus negócios:

Aí nós começamos produzir e ele falou: - Oh, vai vender pro mercado aí que eu não dou conta de vocês não [em função da grande produção obtida pela terceirizada]. Pode... Pode vender pro mercado. Busque o seu mercado (Entrevistado 2).

Aí um tempo ele começou a terceirizar a empresa dele, aí foi aonde que ele me ofereceu a parte de acessório de banheiro, que eu comecei aqui só com acessório de banheiro Eu fazia o acessório pra ele [...] fiquei mais uns 2 anos mais ou menos com ele, trabalhando [...] (Entrevistado 3).

Aí houve um período difícil aí com essa pessoa nós fomos fabricar nossa própria torneira. Eu lancei a marca nossa em 2003 (Entrevistado 1).

Dessa forma, o contexto influenciou a mudança estratégica das empresas que atualmente são associadas, visto que passaram de fornecedores de 
Julio Ernesto Colla • Sergio Bulgacov

peças e componentes para a conquista de mercados próprios para seus produtos.

Por outro enfoque, o contexto aparece no processo de strategizing (WILSON; JARZABKOWSKI, 2004) como indutor da informalidade tanto no gerenciamento quanto no processo de criar a estratégia. Um fato que auxilia na compreensão do contexto na informalidade entre as empresas associadas é o surgimento de uma empresa em um município próximo de Loanda, colocando-o no APL.

Por um acaso [...] vim passear no meu tio [...] ele estava começando [...] aí virei fabricante de torneira (Entrevistado 4).

O contexto nos estágios iniciais das empresas associadas parece criar transferências de práticas baseadas na simplicidade e na informalidade, com a posterior transposição desses métodos gerenciais e estratégicos para as empresas não-associadas, já que a existência destas é cronologicamente posterior à daquelas, e por espelharem suas ações nas empresas associadas.

Ética: sob a perspectiva dos empresários do APL de Metias Sanitários, há a forte vinculação entre os conceitos de ética e cumprimento das leis.

A presença desse elemento entre as empresas associadas parece ser originada do receio em retornar a condições financeiras, econômicas e sociais anteriores ao início das atividades empresariais, pois o não cumprimento da legislação pode acarretar o término das atividades empresariais e das relações pessoais originadas com elas. Dessa forma, a ética surge como explicação de determinadas ações empresariais.

Pra tá na associação, né, ser sócios, são filiados ali somente aqueles que estão legalmente com as normas, né, teve alguns que quis entrar que não tava [...] os que infelizmente não estão de acordo com a lei, esses aí nós não trouxemos para o nosso grupo (Entrevistado 2).

Tem que fazer a coisa certa, ou você não consegue nem uma licença, nem ligar o transformador, né. E hoje a gente procura fazer... fazer certo. E tem empresas que abriu depois de mim que faz errado, muito errado, e pratica concorrência desleal né, pra nós (Entrevistado 1) . 
Prática e Conteúdo Estratégico em Redes de Empresas: estudo no APL de metais sanitários de Loanda/PR.

A gente tenta trabalhar certo, mas só que... a gente fica assim, né... chateado porque vê que tem gente que não tá trabalhando certo e tá sobrevivendo, tá se saindo melhor do que a gente (Entrevistado 3).

[...] a gente não pode se sujeitar a ter um problema no futuro por conta de algum tipo de situação [...], não pode mesmo (Entrevistada 5).

Apesar de Clegg, Carter e Komberger (2004) alertarem para o fato de a competitividade estimular ações que fazem os estrategistas perderem os limites éticos, os gerentes das empresas associadas parecem respeitar os limites legais e de concorrências. Esse respeito decorre, também, do fato de que os relacionamentos pessoais são anteriores aos empreendimentos, sugerindo que a ética na estratégia está embasada em fatores pessoais. Apesar de não aparecer de forma explícita entre os empresários não-associados, a ética acompanha a lógica das empresas associadas, embora os empresários não-associados serem acusados, pelos empresários associados, de descumprimento da totalidade da legislação.

Instituições: a influência institucional descrita por Clegg, Carter e Komberger (2004) parece estar presente nas empresas associadas em função da busca da legitimidade. Essa busca acontece em função de, no início do APL, ter havido abusos com relação à legislação ambiental (fato que auxilia na compreensão da ética no processo de criação da estratégia), fomentando uma atitude negativa da comunidade em relação às empresas:

Depois que montou a associação que nós começamos a trabalhar em grupo que foi aonde foi melhorando, só que a gente tem um conceito meio ruim, sabe, ainda (Entrevistado 3).

Foi até um, não sei se foi, um erro nosso, né, porque a imagem da indústria de metais sanitários de Loanda não era só....só...regional aqui não, ela era muito... até, vamos dizer assim, estadual, nacional, até eu já ouvi coisas fora do estado aqui, né [...]. E... então, só que nós não fizemos uma campanha interna na própria... No próprio quintal vamos dizer assim, nós não fizemos essa campanha defendendo, falando: - Oh, pessoal, era assim, mas agora é assado, então não houve essa campanha, foi até um desleixo nosso, um erro, né, mas através de alguns cursos que 
Julio Ernesto Colla • Sergio Bulgacov

nós trouxemos aqui nós convidamos a comunidade, fizemos até uma... Trouxemos até a Orquestra Sinfônica de Vila Lobos, lá de violões de Vila Lobos, né, de Curitiba, e ali todos eles falavam: - Oh! Loanda, capital da torneira, tal, tal, tal, e... Daí o povo... Hoje eu já vi pessoas que, fora do segmento, defendendo os metais sanitários, né (Entrevistado 2).

O pessoal, alguém fazer alguma campanha para tirar essa imagem negativa de Loanda. Pra... própria população daqui, porque tem gente que diz que isso é o fim do mundo uma indústria dessa dentro da cidade, e não é (Entrevistado 1$)$.

O alerta de Clegg, Carter e Komberger (2004), de que busca pela legitimidade e a consequente possibilidade de isomorfismo pode levar as organizações ao desalinhamento do ambiente organizacional, não parece preocupar os empresários do APL de Metais Sanitários.

Poder: no processo de strategizing das empresas associadas, é notada a presença do poder como condição de levar uma mensagem oficial das organizações, pois ao gerente principal de uma empresa é inerente a ânsia em transmitir suas crenças e princípios. Nesse sentido, dentre os empresários associados, o poder é utilizado próximo ao que foi utilizado para a explicação da influência das instituições no processo de estratégia, já que a busca pela legitimidade também pode ser encarada como sendo a tentativa de transmissão de uma mensagem oficial. Dessa forma, dentre os entrevistados associados, é percebida a tentativa de exercer poder e influência dentro do processo de aceitação junto à comunidade.

Loanda vive em torno de fábrica de torneiras, sem isso aqui, Loanda morre (Entrevistado 1).

[...] é a capital da torneira mesmo. É uma cidade com 23 mil habitantes, uma região (os quatro municípios que integram o APL) com um povo de mais ou menos umas 60 mil pessoas. Gera 3 mil empregos, então quer dizer que... é importante para a região [...] (Entrevistado 2).

Sobre as críticas de alguns integrantes da comunidade: 
[...] ainda tem, mas isso é pessoas que não tem o que fazer, né? (Entrevistado 3).

Os relatos acima condizem com a preocupação de Clegg, Carter e Komberger (2004) quando tratam do entendimento das decisões tomadas e de seu motivo, como a forma como as elites dominantes exercem pressão $e$ controle no processo estratégico, visto que as mensagens carregam sinais de poder econômico frente à região em que se encontra o APL.

Resultados da Estratégia: a análise da preocupação de Whittington (2004) sobre a quem interessa o resultado da estratégia - à empresa ou ao estrategista - possui, na rede estudada, características típicas de pequenas empresas familiares, tanto entre as empresas associadas ou não, quanto nas ativas ou reativas, referente ao conteúdo estratégico. Existe uma mistura entre os interesses das empresas e os interesses individuais, pois é bastante comum entre os empresários de forma geral as respostas na primeira pessoa do singular quando tratam de assuntos da empresa.

Sobre o porte atual da empresa, a resposta de um empresário foi precedida de sorriso de satisfação e orgulho:

[...] a gente nunca imagina não viu. [...] no começo é muito difícil. [...] mas eu não tinha sonhado muito chegar onde eu cheguei não (Entrevistado 1).

Ou ainda expõe:

[...] tudo isso não, mas a gente... tinha uma noção de mercado. [...] aí foi crescendo, foi crescendo e graças a Deus chegamos aonde estamos hoje (Entrevistado 3).

Dos entrevistados associados, um relatou ter noção dos caminhos da empresa:

Eu acredito que... imaginava que chegaria sim, até onde vai chegar eu... eu tenho noção do que vai acontecer (Entrevistado 4). 
Julio Ernesto Colla • Sergio Bulgacov

Questionada sobre as ameaças à perenidade e os resultados futuros da empresa, a entrevistada relatou de maneira a compará-los a seu próprio:

\section{[...] ameaça a minha integridade (Entrevistado 5).}

Os empresários, de forma geral, apresentam grande satisfação com o desempenho das empresas, pois, no momento em que eram questionados sobre os resultados, surgia em seus semblantes uma nítida postura de orgulho. Nos entrevistados há um interesse comum entre os resultados da estratégia, tanto à empresa quanto aos empresários, visto que os dois se fundem.

Stakeholders: diante da preocupação de Wilson e Jarzabkowski (2004) sobre a postura do estrategista frente a stakeholders diferentes, foi encontrada sensível modificação de comportamentos. Essa transformação tem sido criada por relações de poder diante do stakeholder envolvido, havendo uma postura efetiva frente aqueles sobre os quais é possível exercer algum tipo de influência.

Sobre os empregados das empresas associadas que buscam negociar maiores salários com outras empresas também associadas, há uma troca de informações centralizada na sede da associação para que isso não aconteça, evitando, assim, disputas por empregados e consequente aumento dos salários.

[...] o empregado se apresenta e diz: eu faço isso, faço aquilo, se você me pagar tanto eu venho. É o que a gente ta parando de fazer, era assim [...] fazia um leilão. Trabalha seis meses, ganhava seguro (seguro desemprego) [...] (Entrevistado 3).

[...] às vezes tem uma empresa roubando funcionário da outra que é um problema isso né, que é uma outra coisa que a gente vem tentando resolver, mas ainda tem aí um ou dois que não respeitam muito, mas a gente vem, vem batendo muito em cima disso [...] eu tenho que reconhecer que diminuiu [...] (Entrevistado 5).

Em relação aos empregados, surge também a postura inerte devido à constatação de falta de mão de obra entre os entrevistados associados e os não-associados (ativos ou reativos quanto ao conteúdo estratégico): 
Prática e Conteúdo Estratégico em Redes de Empresas: estudo no APL de metais sanitários de Loanda/PR.

Tem mão de obra? Não tem. Não existe mão de obra (Entrevistado 1 ).

[...] eu não tenho uma ficha, vamos supor de um homem que tá querendo trabalhar [...] a região toda tem dificuldade de mão de obra (Entrevistado 4).

Essa falta de mão de obra acarreta uma fragilidade das empresas associadas e não-associadas:

Eu tenho que dar meu seguro desemprego, meus três meses de seguro, mais o meu salário aqui, quer dizer, a gente precisa de mão de obra e se sujeita a isso (Entrevistado 3).

Outro fato que demonstra a postura inerte de strategizing se dá com os organismos ambientais, visto que as ações propostas são imediatamente acatadas. Essa atitude acontece em função do caráter coercitivo do órgão, como também em função do que foi tratado no item sobre ética:

[...] a gente já teve muito problema aqui [...], de meio ambiente, de tudo, ministério do trabalho [...] eu, quando comecei, eu já comecei mais certo que os outros. Eu já num comecei tão errado (Entrevistado 1).

[...] esses dias teve uma promotora. Veio a promotoria de Curitiba aqui. Veio, fiscalizou tudo, tal e tal, viu, não tinha nada de errado [...] (Entrevistado 3).

O relato do entrevistado sobre uma conversa com um funcionário do órgão ambiental é bastante ilustrativo sobre o assunto:

Chicófi, misericórdia, você me fala o que eu faço com essa água. Quer que eu tomo ela? Porque você não falam (Entrevistado 3).

Os relatos acima parecem ilustrar as duas situações encontradas: postura efetiva, frente aos stakeholders que são passíveis de influência pelo poder que detêm as empresas, e postura inerte em relação àqueles que possuem 
poder sobre a empresa, principalmente aqueles que possuem condições punitivas sobre os negócios.

Linguagem: os fenômenos relativos à comunicação dos entrevistados associados e dos não-associados (ativos ou reativos quanto ao conteúdo estratégico) representam a simplicidade com que eles se comunicam. A possibilidade de encontrar um referencial para entendimento é obtido da estatística lexical, através do coeficiente de variedade vocabular, que estipula a relação entre o número de palavras diferentes e o número total de palavras encontradas na entrevista (RICHARDSON, 1999). Nesse sentido, os entrevistados associados apresentaram média de 0,2302 contra 0,2333 dos nãoassociados, sugerindo uma capacidade léxica semelhante e reduzida entre os entrevistados, independentemente de serem ou não associados. A preocupação com a linguagem é encontrada em Clegg, Carter e Komberger (2004) e Wilson e Jarzabkowski (2004), porque é válido conhecer a linguagem da estratégia e como essa linguagem interfere no processo de sua criação. Os dados indicam que, através da análise lexical dos entrevistados e a comparação linear daqueles que são associados e dos não-associados, existe proximidade dos recursos linguísticos. $\mathrm{O}$ que se encontrou em termos linguísticos auxilia a compreensão da simplicidade da forma de comunicação entre os empresários do APL de Metais Sanitários e a decorrente simplicidade no processo gerencial e estratégico.

\subsection{Análise Quantitativa}

O construto relativo aos comportamentos estratégicos dos integrantes do APL de Metais Sanitários foi considerado sob as perspectivas dos dois grupos pré-classificados desta pesquisa: as empresas associadas e as nãoassociadas à AIMES e as empresas ativas e as reativas quanto ao conteúdo estratégico. Elaborado por meio da fase qualitativa e da base teórico-empírica, o construto foi composto por 11 indicadores em escala intervalar e métrica de classificação somada (Likert). O início da análise ocorreu com a verificação missing values entre as variáveis, o que ocorreu em função da coleta dos dados ter sido administrada pelo próprio pesquisador, seguida de sucessivos contatos pessoais e telefônicos.

Optou-se, primeiramente, pela análise de correlação de Spearman entre as variáveis, conforme Tabela 2 . Houve a retirada, para fins de apresenta- 
ção nesse momento, das variáveis viajar sozinho e procurar a igreja como comportamento estratégico dos respondentes, por não apresentar correlações com outros indicadores.

O teste apontou as principais correlações entre os fatores: conversas familiares, isolamento e leitura como prática estratégica e conversas com pessoas do ramo, happy hour, conversas com empregados de outras empresas, conversas com pessoas do ramo e conversas com empregados. Também foi encontrada correlação entre conversas com pessoas de fora do ramo e o momento de folga. Essas correlações informam que os empresários podem ser classificados em três classes quanto à prática estratégica: os empresários que tendem a possuír comportamento recatado quando pensam a estratégia; os empresários que tendem a se reunir com outras pessoas do ramo de metais sanitários, sejam seus empregados ou não, em reuniões informais; e aqueles que conversam com pessoas de fora do ramo de metais sanitários em situações fora do cotidiano empresarial.

Na perspectiva das empresas associadas e das não-associadas (Tabela 3), os empresários somente poderão ser considerados como grupos distintos no momento de fazer a estratégia nos indicadores isolamento e conversas com familiares. Essas práticas são utilizadas pelas empresas associadas. Outro indicador em que é possível considerá-los como grupos distintos no momento de fazer a estratégia é falar com empregados das outras empresas. Nesse indicador, a utilização dessa prática estratégica foi encontrada nas empresas não-associadas. Essa constatação apresenta a ideia de que as organizações associadas possuem liderança nas práticas gerenciais no APL de Metais Sanitários e as não-associadas procuram agir de maneira semelhante.

O comportamento estratégico dos respondentes, sob a ótica das empresas ativas e reativas quanto ao conteúdo estratégico (Tabela 4), apresenta evidencias estatísticas de formação de grupos diferentes apenas no indicador happy hour. Essa prática é utilizada pelos empresários das empresas reativas. Em função de haver apenas um indicador em que foram encontradas diferenças estatísticas, é possível entender que os empresários de empresas ativas e reativas quanto ao conteúdo estratégico comportam-se de maneira praticamente semelhante ao elaborarem a estratégia, ou ainda que os empresários das empresas reativas não possuem característica ou preocupação com pensamento estratégico em função da dependência operacional das empresas ativas. 
Os indicadores das práticas de comportamento estratégico, quando submetidos aos quatro clusters base deste trabalho, indicam que não há diferenças estatísticas significantes no que diz respeito aos itens pesquisados na composição da estratégia, conforme demonstra a Tabela 2, a seguir:

Tabela 2: Análise de correlação de Spearman das práticas estratégicas.

\begin{tabular}{|c|c|c|c|c|c|c|c|c|c|}
\hline & Isolamento & $\begin{array}{l}\text { Conversas } \\
\text { com pessoas } \\
\text { fora do } \\
\text { ramo }\end{array}$ & $\begin{array}{l}\text { Conversas } \\
\text { familiares }\end{array}$ & Folga & $\begin{array}{c}\text { Happy } \\
\text { Hour }\end{array}$ & Ler & $\begin{array}{c}\text { Falar com } \\
\text { empregados } \\
\text { de outras } \\
\text { empresas }\end{array}$ & $\begin{array}{l}\text { Conversas } \\
\text { com pessoas } \\
\text { do ramo }\end{array}$ & $\begin{array}{c}\text { Conversas } \\
\text { com os } \\
\text { emprega- } \\
\text { dos }\end{array}$ \\
\hline Isolamento & 1,000 & ,123 &, $420(*)$ & ,244 & ,282 &,- 015 & ,018 & ,179 & ,217 \\
\hline $\begin{array}{l}\text { Conversas } \\
\text { com pessoas } \\
\text { fora do } \\
\text { ramo }\end{array}$ & ,123 & 1,000 & ,147 &, $367\left({ }^{*}\right)$ & -,012 & ,044 & ,320 & ,127 & ,216 \\
\hline $\begin{array}{l}\text { Conversas } \\
\text { familiares }\end{array}$ &, $420\left(^{*}\right)$ & ,147 & 1,000 &,- 004 &,- 162 &, $474(* *)$ &,- 310 &,- 048 & ,208 \\
\hline Folga &, 244 &, $367\left({ }^{*}\right)$ &,- 004 & 1,000 &, 015 & ,032 & ,172 &, 042 & ,184 \\
\hline $\begin{array}{l}\text { Happy } \\
\text { Hour }\end{array}$ & ,282 &,- 012 &,- 162 & ,015 & 1,000 &,- 285 &, $372\left(^{*}\right)$ &, $499(* *)$ & ,156 \\
\hline Ler &,- 015 &, 044 &, $474(* *)$ & ,032 &,- 285 & 1,000 &,- 278 &, 058 &, 044 \\
\hline $\begin{array}{l}\text { Falar com } \\
\text { empregados } \\
\text { de outras } \\
\text { empresas }\end{array}$ & ,018 & ,320 &,- 310 & , 172 &, $372\left({ }^{*}\right)$ &,- 278 & 1,000 &, $448(* *)$ & ,131 \\
\hline $\begin{array}{l}\text { Conversas } \\
\text { com pessoas } \\
\text { do ramo }\end{array}$ & ,179 & ,127 &,- 048 & ,042 &, 499 (**) & ,058 &, $448(* *)$ & 1,000 &, $534\left({ }^{* *}\right)$ \\
\hline $\begin{array}{l}\text { Conversas } \\
\text { com os } \\
\text { empregados }\end{array}$ & ,217 & ,216 & ,208 & ,184 & ,156 & ,044 & ,131 &, $534(* *)$ & 1,000 \\
\hline
\end{tabular}

Fonte: Dados primários.

Nota: * correlação significantes ao nível de 0,05.

** correlação significante ao nível de 0,01.

Dessa forma, as diferenças de faturamento, principal interesse deste trabalho na análise de cluster, não é diferenciador das posturas estratégicas entre os dirigentes das empresas do APL de Metais Sanitários.

\section{Conclusão}

Os dados analisados neste trabalho informam que os empresários do APL de Metais Sanitários atuam de forma semelhante em relação ao 
strategizing, sendo encontradas apenas pequenas diferenças de comportamento estratégico.

No APL de Metais Sanitários há grande influência da empresa pioneira no sistema estratégico das empresas associadas (ativas ou reativas quanto ao conteúdo estratégico) e não-associadas (ativas ou reativas quanto ao conteúdo estratégico), sendo que identificou-se grande transferência das práticas estratégicas entre as empresas.

Em relação aos principais influenciadores das práticas estratégicas apresentados, apenas entre as empresas associadas foi encontrada a presença de atores não humanos no processo de criação da estratégia. As capacidades e conhecimentos são semelhantes em todos os grupos analisados pela pesquisa e contribuem para a simplificação e o conservadorismo das práticas estratégicas, haja vista a formação individual de diversas origens. O contexto é influenciador bastante presente nas práticas estratégicas e contribui como indutor da informalidade e simplicidade da criação da estratégia. As práticas estratégicas decorrentes da empresa pioneira influenciaram primeiramente as empresa associadas (ativas ou reativas quanto ao conteúdo estratégico), em decorrência da proximidade, e posteriormente as não-associadas (ativas ou reativas quanto ao conteúdo estratégico). A ética, muito presente no processo de criação da estratégia, em especial quando se trata do contexto, é influenciada por relações individuais anteriores aos negócios, independente dos grupos analisados. A busca por legitimidade e o consequente isomorfismo organizacional coloca o elemento instituições como grande influenciador no processo de formação estratégica no APL de Metais Sanitários, em especial nas empresas associadas e ativas quanto ao conteúdo estratégico. O poder

Tabela 3: Teste de comparação de médias para as empresas associadas e não-associadas.

\begin{tabular}{|c|c|c|c|c|c|c|c|c|c|c|c|c|}
\hline & & Isolamento & $\begin{array}{c}\text { Conversas } \\
\text { com } \\
\text { pessoas } \\
\text { fora do } \\
\text { ramo }\end{array}$ & $\begin{array}{l}\text { Conversas } \\
\text { familiares }\end{array}$ & Folga & $\begin{array}{l}\text { Viajar } \\
\text { sozinho }\end{array}$ & $\begin{array}{c}\text { Happy } \\
\text { Hour }\end{array}$ & Ler & Igreja & $\begin{array}{c}\text { Falar com } \\
\text { emprega- } \\
\text { dos de } \\
\text { outras } \\
\text { empresas }\end{array}$ & $\begin{array}{c}\text { Conversas } \\
\text { com } \\
\text { pessoas do } \\
\text { ramo }\end{array}$ & $\begin{array}{c}\text { Conversas } \\
\text { com os } \\
\text { emprega- } \\
\text { dos }\end{array}$ \\
\hline \multicolumn{2}{|l|}{$\begin{array}{l}\text { Mann- } \\
\text { Whitney U }\end{array}$} & 77,00 & 95,00 & 58,00 & 101,50 & 133,50 & 116,00 & 116,00 & 101,50 & 80,500 & 124,00 & 90,000 \\
\hline \multicolumn{2}{|l|}{ Wilcoxon W } & 308,00 & 326,00 & 289,00 & 332,50 & 364,50 & 207,00 & 347,00 & 332,50 & 171,50 & 215,00 & 321,00 \\
\hline \multicolumn{2}{|l|}{ Z } & $-2,264$ & $-1,536$ & $-2,897$ & $-1,397$ &,- 132 &,- 762 &,- 760 & $-1,335$ & $-2,110$ &,- 554 & $-1,768$ \\
\hline \multicolumn{2}{|c|}{ Significância } & ,024 & , 125 & ,004 & ,162 & 895 & ,446 & ,447 & , 182 & ,035 &, 580 & ,077 \\
\hline \multirow{2}{*}{$\begin{array}{l}\text { Ranking } \\
\text { médio } \\
\text { quanto } \\
\text { ao associa- } \\
\text { tivismo }\end{array}$} & Sim & 22,08 & 20,69 & 23,54 & 20,19 & 17,73 & 15,92 & 19,08 & 20,19 & 13,19 & 16,54 & 21,08 \\
\hline & Não & 14,67 & 15,52 & 13,76 & 15,83 & 17,36 & 18,48 & 16,52 & 15,83 & 20,17 & 18,10 & 15,29 \\
\hline
\end{tabular}

Fonte: Dados primários. 
Julio Ernesto Colla • Sergio Bulgacov

Tabela 4: Teste de comparação de médias para as empresas ativas e reativas.

\begin{tabular}{|c|c|c|c|c|c|c|c|c|c|c|c|c|}
\hline & & Isolamento & $\begin{array}{c}\text { Conversas } \\
\text { com } \\
\text { pessoas } \\
\text { fora do } \\
\text { ramo }\end{array}$ & $\begin{array}{l}\text { Conversas } \\
\text { familiares }\end{array}$ & Folga & $\begin{array}{l}\text { Viajar } \\
\text { sozinho }\end{array}$ & $\begin{array}{c}\text { Happy } \\
\text { Hour }\end{array}$ & Ler & Igreja & $\begin{array}{c}\text { Falar com } \\
\text { emprega- } \\
\text { dos de } \\
\text { outras } \\
\text { empresas }\end{array}$ & $\begin{array}{c}\text { Conversas } \\
\text { com } \\
\text { pessoas do } \\
\text { ramo }\end{array}$ & $\begin{array}{c}\text { Conversas } \\
\text { com os } \\
\text { emprega- } \\
\text { dos }\end{array}$ \\
\hline \multicolumn{2}{|l|}{$\begin{array}{l}\text { Mann- } \\
\text { Whitney U }\end{array}$} & 75,00 & 94,000 & 65,000 & 105,00 & 111,00 & 56,000 & 66,000 & 79,500 & 74,500 & 83,000 & 102,50 \\
\hline \multicolumn{2}{|l|}{ Wilcoxon W } & 120,00 & 419,00 & 110,00 & 430,00 & 436,00 & 381,00 & 111,00 & 404,50 & 399,50 & 408,00 & 147,50 \\
\hline \multicolumn{2}{|l|}{ Z } & $-1,572$ &,- 754 & $-1,931$ &,- 330 &,- 073 & $-2,314$ & $-1,900$ & $-1,387$ & $-1,577$ & $-1,440$ &,- 419 \\
\hline \multicolumn{2}{|c|}{ Significância } & ,116 &, 451 & 054 & ,742 & ,942 &, 021 & 057 & , 166 &, 115 & 150 & ,675 \\
\hline \multirow{2}{*}{$\begin{array}{l}\text { Ranking } \\
\text { médio } \\
\text { quanto } \\
\text { ao associa- } \\
\text { tivismo }\end{array}$} & Sim & 19,00 & 16,76 & 19,40 & 17,20 & 17,44 & 15,24 & 19,36 & 16,18 & 15,98 & 16,32 & 17,90 \\
\hline & Não & 13,33 & 19,56 & 12,22 & 18,33 & 17,67 & 23,78 & 12,33 & 21,17 & 21,72 & 20,78 & 16,39 \\
\hline
\end{tabular}

Fonte: Dados primários.

no processo de strategizing é mais presente nas empresas associadas e ativas, como na tentativa de transmissão do discurso oficial empresarial de poder econômico e no processo de aceitação junto à comunidade. Quanto ao resultado da estratégia, foi encontrada uma situação típica de pequenas empresas familiares, em que há uma fusão entre os interesses organizacionais e individuais, independente do grupo de empresas utilizado para a análise. No que tange aos stakeholders, há duas formas de comportamento distintas: a primeira acontece quando é possível exercer algum tipo de influência, e a segunda ocorre quando não há essa possibilidade. Essas duas posturas são mais encontradas nas empresas ativas, independente de serem ativas ou reativas quanto ao conteúdo estratégico. A linguagem, último elemento teórico analisado, aparece como outro elemento que vem a corroborar a simplicidade do processo estratégico e gerencial das empresas que compóem o APL de Metais Sanitários, independente de serem associadas ou não, ativas ou reativas quanto ao conteúdo estratégico.

Em relação à possibilidade de correlação das principais práticas estratégicas adotadas foi possível encontrar três posturas distintas entre os respondentes: a postura dos empresários que possuem um comportamento recatado quando cria a estratégia; a dos empresários que tendem a se reunir informalmente com outras pessoas do ramo de metais sanitários, sejam seus empregados ou não; e a daqueles que conversam com pessoas de fora do ramo de metais sanitários, em situações externas ao cotidiano empresarial.

Em relação à situação de associativismo no processo de strategizing, os empresários associados tendem mais ao isolamento e a conversas com familiares, e os não associados a conversas com empregados de outras empresas. 
Tabela 5: Teste Kruskal-Wallis para o cluster base.

\begin{tabular}{|c|c|c|c|c|c|c|c|c|c|c|c|c|}
\hline & & Isolamento & $\begin{array}{c}\text { Conversas } \\
\text { com } \\
\text { pessoas } \\
\text { fora do } \\
\text { ramo }\end{array}$ & $\begin{array}{l}\text { Conversas } \\
\text { familiares }\end{array}$ & Folga & $\begin{array}{l}\text { Viajar } \\
\text { sozinho }\end{array}$ & $\begin{array}{l}\text { Happy } \\
\text { Hour }\end{array}$ & Ler & Igreja & $\begin{array}{c}\text { Falar com } \\
\text { emprega- } \\
\text { dos de } \\
\text { outras } \\
\text { empresas } \\
\end{array}$ & $\begin{array}{c}\text { Conversas } \\
\text { com } \\
\text { pessoas do } \\
\text { ramo }\end{array}$ & $\begin{array}{c}\text { Conversas } \\
\text { com os } \\
\text { emprega- } \\
\text { dos }\end{array}$ \\
\hline \multicolumn{2}{|c|}{ Significância } & ,487 & 269 & 249 & ,055 & 596 & ,363 & , 058 & 133 & 287 & ,985 & ,197 \\
\hline \multirow{4}{*}{$\begin{array}{l}\text { Ranking } \\
\text { médio } \\
\text { clusters }\end{array}$} & 1 & 13,95 & 18,64 & 14,50 & 16,91 & 16,73 & 20,68 & 14,32 & 19,50 & 19,32 & 17,82 & 13,68 \\
\hline & 2 & 19,50 & 23,33 & 23,33 & 23,33 & 21,00 & 12,92 & 26,42 & 23,25 & 11,83 & 16,50 & 19,67 \\
\hline & 3 & 18,50 & 14,00 & 19,86 & 10,50 & 15,14 & 15,07 & 18,79 & 12,14 & 15,57 & 18,07 & 22,93 \\
\hline & 4 & 19,50 & 15,20 & 15,65 & 19,55 & 17,90 & 18,45 & 14,75 & 15,60 & 20,25 & 17,35 & 16,60 \\
\hline
\end{tabular}

Fonte: Dados primários.

O happy hour, por sua vez, diferencia a postura dos dirigentes das empresas reativas quanto ao conteúdo estratégico

No que tange ao comportamento estratégico dos empresários de acordo com o agrupamento analítico base, não foram encontradas diferenças estatísticas nos indicadores analisados, o que informa que o processo de strategizing pode não ser influenciado pelo faturamento das empresas.

$\mathrm{O}$ presente artigo pretendeu contribuir com o entendimento do strategizing em redes de empresas. Para entende-lo, são necessários novos trabalhos na área, em outras redes organizacionais industriais e de prestação de serviços, o que possibilitará a generalização e a sedimentação dos conhecimentos a respeito do strategizing.

\section{Pratice end Content Strategic in Network Organizations: a study in APL de sanitary metals of the Loanda/PR}

\section{Abstract}

This article aims to describe the main strategical practices in the network of companies that comprise the APL of the Sanitary Metals de Loanda, Paraná. The theoretical framework of this strategy as practice and strategic content in network companies. Two independent and complementary methodologies had been adopted: first, an exploratory and qualitative phase result of the theoretical structure to the design of the categories of analysis; after that, a survey research for the application of the study to the population consisting of the integrant companies of Local Productive Arrangement. The methodological procedures, therefore, were multiple and descriptive and explanatory nature. The main meetings indicate that 
Julio Ernesto Colla • Sergio Bulgacov

the leaders of the companies studied have adopted a strategy process informal and simplified, with a large transfer of strategic practices between managers and the adoption of three different positions: The main finds indicate that the managers of the companies studied present a informal and simplified strategic process; there are transfers of the strategical practices between managers; the managers adopt three distinct positions: a) coy behavior; b) those who tend to meet with people in the industry and c) those who talker with people from outside the industry.

Key-words: Strategic Practice. Content Strategy. Organizational Networks.

\section{REFERÊNCIAS}

ANSOFF, H. I. Strategies for diversification. Harvard Business Review, Boston. v. 35, n. 5, p. 113-125, 1957.

BARDIN, L. Análise de conteúdo. Lisboa: Edições 70, 1977.

BULGACOV, S. Conteúdo e processo estratégico: estudo comparativo de casos na indústria alimentícia do Paraná. 1997. Tese (Doutorado em Administração) - Escola de Administração de Empresas de São Paulo, Fundação Getúlio Vargas. São Paulo:, 1997.

BULGACOV, S, et al. Administração estratégica: teoria e prática. São Paulo: Atlas, 2007.

CHAKRAVARTHY, B. S.; DOZ, I. Strategy process research: focusing on corporate self-renewal. Strategic Management Journal, London, v. 13, 1992.

CLEGG, S.; CARTER, C.; KOMBERGER, M. Get up, I feel like being a strategy machine. European Management Review, Hampshire v. 1, n. 1, p. 21-28, 2004.

CRESWELL, J. C. Projeto de Pesquisa: métodos qualitativo, quantitativo e misto. 2. ed. Porto Alegre: Artmed, 2007.

DENIS, J. L; LANGLEY, A.; ROULEAU, L. Studying strategizing in pluralistic contexts: a methodological agenda, 2004. Disponível em: <http:// www.strategy-as-practice.org >. Acesso em: $1^{\circ}$ fev. 2008.

FIGUEIREDO, R. S.; ZAMBOM, A. C. A empresa vista como elo da cadeia de produção e distribuição. Teoria e Prática da Administração: Artigos selecionados da Revista de Administração da USP. Rio de Janeiro: Elsevier, 2005. 
Prática e Conteúdo Estratégico em Redes de Empresas: estudo no APL de metais sanitários de Loanda/PR.

FLICK, U. Uma introdução à pesquisa qualitativa. 2. ed. Porto Alegre: Bookman, 2004.

GIMENEZ, F. A. P. O estrategista na pequena empresa. Maringá: [s.n.], 2000.

GRANT, R. M. Corporate Strategy: Managing Scope and Strategy Content. In: PETTIGREW, A.; THOMAS, H.; WHITTINGTON, R. (Eds.). Handbook of Strategy and Management. London: Sage, 2002.

IPARDES. Arranjo produtivo local Metais Sanitários de Loanda e Região: estudo de caso. Curitiba: IPARDES, 2006. 57p.

JARZABKOWSKI, P. Strategic practices: an activity theory perspective on continuity and change. Journal of Management Studies, London, v. 40, n. 1, p. 23-55, 2003.

2005.

Strategy as practice: an activity-based approach. London: Sage,

MAY, T. Pesquisa social: questões, métodos e processos. 3. ed. Porto Alegre: Artmed, 2004.

MEIRELLES, A. de M.; GONÇALVES, C. A. Uma Abordagem para Estratégia Utilizando Analogias. In. ENCONTRO NACIONAL DA ASSOCIAÇÃO DOS PROGRAMAS DE PÓS-GRADUAÇÃO EM ADMINISTRAÇÃO, 2000, Florianópolis. Anais... Florianópolis, 2000. 1 CD-ROM.

MINTZBERG, H. Generic strategies: toward a comprehensive framework. In: LAMB. R. B.; SHRIVASTAVA, P. (Eds.). Advances in strategic management, Greenwich, Conn., v. 5, p. 1-67, 1988.

PETTIGREW, A. M. The Character and Significance of Strategy Process Research. England: Strategic Management Journal, London, v. 13, p. 5-16, 1992.

PORTER, M. E. Estratégia Competitiva: técnicas para análise de indústria e da concorrência. 16. ed. Rio de Janeiro: Campus. 2004.

RICHARDSON, R. J. Pesquisa social: métodos e técnicas. 3. ed. São Paulo: Atlas, 1989. 
Julio Ernesto Colla $•$ Sergio Bulgacov

WHITTINGTON, R. Strategy as practice. Long Range Planning, London, v. 29, n. 5, p. 731-735, 1996.

O que é estratégia. São Paulo: Pioneira Thomson Learning, 2002. 173 p. The work of strategizing and organizing: for a practice perspective.

Strategic Organization, London, vol 1, p. 119-127, feb. 2003.

Strategy after modernism: recovering practice. European

Management Review, Hampshire, v. 1, n. 1, p. 62-68, 2004.

WHITTINGTON, R.; JOHNSON, G.; MELIN, L. The emerging field of strategy practice: some links, a trap, a choice and a confusion. Anais... EGOS Colloquium. Ljubljana, Slovenia, july 2004.

WILSON, D. C.; JARZABKOWSKI, P. Thinking and acting strategically: new challenges for interrogating strategy. European Management Review, Hampshire, v. 1, n. 1, p. 14-20, 2004. 